\title{
VERBAL DISPUTES AND DEEP CONCEPTUAL DISAGREEMENTS
}

\author{
Daniel Cohnitz
}

Utrecht University

\begin{abstract}
To say that a philosophical dispute is 'merely verbal' seems to be an important diagnosis. If that diagnosis is correct for a particular dispute, then the right thing to do would be to declare that dispute to be over. The topic of what the disputing parties were fighting over was just a pseudo-problem (thus not really a problem), or at least - if there is a sense in which also merely verbal disputes indicate some problem, for example, insufficient clarity of terminology - this problem is not substantial, or not as substantial as the disputing parties believed their problem initially to be. In this paper I will try to clarify what it means if we diagnose that two arguing parties are having a merely verbal dispute.
\end{abstract}

Keywords: verbal dispute, conceptual disagreement, talking past each other

DOI: https//doi.org/10.3176/tr.2020.3.02

\section{Introduction}

To say that a philosophical dispute is 'merely verbal' seems to be an important diagnosis. If that diagnosis is correct for a particular dispute, then the right thing to do would be to declare that dispute to be over. The topic of what the disputing parties were fighting over was just a pseudo-problem (thus not really a problem), or at least - if there is a sense in which also merely verbal disputes indicate some problem - for example, insufficient clarity of terminology - this problem is not substantial, or not as substantial as the disputing parties believed their problem initially to be.

Hence diagnosing merely verbal disputes would be one way in which we can make philosophical progress. Not that we would actually solve philosophical problems that way, we would rather dissolve philosophical problems that way. I guess that some of us think that - insofar as there are genuine philosophical problems - there is anyway only this way of getting rid of them, viz. by dissolving them. However, even those 
philosophers who believe that there are genuine substantial philosophical problems would probably agree that some philosophical disputes were or are merely verbal, and that diagnosing which are is important for making some progress in philosophy.

However, my allusion to logical positivism in this last remark also leads to a second motivation for clearing up the notion of a merely verbal dispute. If ontological and logical anti-realists are right, then there are entire philosophical areas in which philosophers are constantly involved in merely verbal disputes and that diagnosis should lead to anti-realist consequences. According to such anti-realists, the debate between, for example, endurantists and perdurantists about whether temporal parts exist, is merely verbal, which shows that there just is no fact of the matter that both parties are talking about. Here the plausibility of a substantial philosophical thesis, namely ontological anti-realism, depends on whether (a) the diagnosis that the parties involved in the dispute are having a merely verbal dispute in whatever regimented sense really leads to anti-realist conclusions, and (b) whether the respective disputes are merely verbal in that regimented sense. In this paper I will try to clarify what it means if we diagnose that two arguing parties are having a merely verbal dispute. As is clear from my introductory remarks, I hope to analyze the notion in a way that is of relevance for metaphilosophy, in particular for the analysis of disputes about ontological and logical anti-realism. I guess that there is a pre-theoretic nontechnical notion of a 'merely verbal dispute' in the vernacular, and it might be interesting to analyze this as well, but I will not try to do that. My project is rather to provide an explication of 'verbal dispute' and cognate expressions for the purpose of clarifying some metaphilosophical issues. In other words: I am well aware that my analysis might conflict with the use of 'verbal dispute' in ordinary language. However, I will argue (or be prepared to argue) that the cases in which the vernacular is different from our regimented conception, the regimented conception is better than the ordinary language notion for the purposes of metaphilosophy.

I will begin by first listing some initial intuitive hypotheses about what it means for two disputing parties to be in a merely verbal dispute and then turn to already existing analyse ${ }^{1}$ of this notion that I will use as steppingstones in order to eventually arrive at my own proposal.

\section{Conditions of adequacy}

When trying to explicate a notion, it is usually best to start with laying down in some detail what conditions of adequacy should be met by the final explicatum. This is often difficult to do in advance, and typically a matter of continuous refinement. But I guess we can start at least with a few intuitions about what it means that two parties in a dispute are having a 'merely verbal dispute', which we might want to preserve in one way or another in the final explication.

\footnotetext{
1 My overview of the existing literature will be a bit eclectic; there have been many contributions in recent years to this topic, but for the point I wish to make it seems to be unnecessary to provide a comprehensive overview.
} 
One thing that we want to say if we diagnose a dispute as 'merely verbal' is that the dispute is somehow insubstantial.

Non-substantiality. There is no point in the dispute, it is a waste of time and resources to continue it.

Although the dispute is insubstantial, it anyway seems or appears to be substantial.

Substantiality appearance. The dispute appears to be substantial at least to the disputing parties.

(That is why we use the diminishing 'merely' when talking about 'merely verbal disputes'. It is merely a verbal dispute, because (at least) the disputing parties believed it was a substantial dispute.)

Another thing that seems implied if we say that a dispute is merely verbal is that the reason for the dispute being insubstantial is a communication failure between the disputing parties.

Communication failure. The reason for the dispute being insubstantial is a communication failure between the disputing parties.

To be more precise:

Linguistic deviance. The reason for that communication failure is a difference in the use or interpretation of some portion of language between the disputing parties.

That is why the dispute is 'merely verbal'.

I believe that these intuitions form the core of what we typically mean when we diagnose a philosophical dispute as being 'merely verbal'. But there are some further intuitions that need to be addressed in our explication.

The first of these is a refinement or specification of the notion of 'portion of language' in the last intuition, and the second is a further clarification of the NonSubstantiality Intuition:

Terminology mismatch. The linguistic problem responsible for the communication failure is that the disputing parties are using some terms in their dispute with different meaning, without noticing it.

Resolvability I. Merely verbal disputes are easily resolvable when detected.

If we combine the last two, we get an idea of how verbal disputes could be resolvable, and perhaps also a methodology to detect them:

Resolvability II. Merely verbal disputes are easily resolvable by introducing terminological distinctions. 
Detectability. Merely verbal disputes are detectable by checking whether the dispute persists between the disputing parties after all possible terminological distinctions are made.

However, as we will see, the last four intuitions have been disputed by some philosophers that also tried to explicate 'merely verbal dispute'. We will have to take their arguments into account when accommodating these latter intuitions.

\section{Jeffrey Goodman on talking past one another}

When I started working on this, I found to my surprise that there were only very few systematic discussions of this topic in argumentation theory (where you might look first for an analysis of merely verbal disagreements), one of the few that I could find at the time is Jeffrey Goodman's analysis in "A critical discussion of talking past one another" (Goodman 2007). Goodman begins his discussion with the stipulation that the expression 'talking past one another' refers to a relation of the type of a progress-hindering communication failure, where progress is to be achieved through communication on the issue at hand.

Goodman then points out that there can be cases of talking past one another where the interlocutors (i) are unaware that they use in their discussion a crucial term with different meaning, and cases (ii) in which the interlocutors know that they have different concepts of a crucial term. ${ }^{2}$ He christens Standard View the view that interlocutors talk past one another if and only if they use a term crucial to their debate with different meaning. Goodman grants the Standard View that it gets all cases right, when the debate is one over ontology, since the Standard View would predict that interlocutors could avoid talking past one another if they agreed on the meaning of that crucial term beforehand. Thus, a discussion about whether God exists might be problematic if both interlocutors have different meanings attached to the term 'God', but they can avoid the possible communication failure by agreeing beforehand on one definition of 'God'.

Goodman eventually rejects the Standard View, though, since he observes that sometimes philosophical disputes are disputes about the meaning of predicate terms (such as 'free will') but this discussion could not, according to Goodman, benefit from the discussing partners agreeing beforehand on a meaning for that term, because finding the meaning of that term was the whole point of the investigation. Goodman then tries to improve on the Standard View by reflecting on which necessary conditions philosophers would have to satisfy in order to be able to avoid talking past each other in the case of discussions about the meaning of predicate terms. He first discusses a suggestion by Peter Van Inwagen, namely that the interlocutors ought to share a second-order functional concept. ${ }^{3}$ Goodman rejects this because

2 As I will show below, (ii) is certainly wrong. But in order to appreciate this, we will have to get the Standard View right first.

3 A second-order conception of some predicate term $P$ is supposed to be the conception that underlies all conceptions of $P$. 
he believes that even philosophers with different second-order functional concepts could avoid talking past one another in his sense. The second suggestion is that the interlocutors must have similar dispositions to classify central applications of the predicate terms in question. Since, as I will show below, this would be actually pretty close to the truth, I quote in full Goodman's argument against this option:

Unfortunately, though, this particular appeal to dispositions also fails to provide adequate conditions for talking past one another. Again, for illustration, suppose that Greta takes freedom of the will to consist in Chisholmian Libertarianism while Hanna takes freedom of the will to consist in Ayerian Compatibilism. It is fairly obvious that Greta may object to Hanna's analysis via presenting a test case that she takes to be a counterexample, yet Hanna simultaneously takes it to be a confirmation of her analysis. For instance, they may clash over whether or not a kleptomaniac is truly acting freely and hence disagree about the implications such a test case has for their respective conceptions of freedom. Even so, Greta and Hanna may still succeed in genuinely communicating about the topic at hand (Goodman 2007: 321).

Thus, according to Goodman, even if two interlocutors cannot agree on whether cases of predicate application are counterexamples to or confirmations of their analyses, they can make progress in communicating about the topic at hand. One should wonder what the argument for this view could possibly be. Perhaps, Hanna and Greta may still succeed in communicating as such, namely if they eventually come to recognize that they are using the crucial term with different (dispositional) meanings. But how could they possibly make any progress on the issue without being able to agree on whether a case should be considered a counterexample or a confirmation? Anyway, let us put that aside for the moment (we will come back to this) and have a look at Goodman's own proposal.

\section{Jeffrey Goodman's account of '(not) talking past each other via $\boldsymbol{P}$ '. $[\mathrm{I}]$ nterlocutors may have a discussion where they genuinely communicate via some crucial term $\mathrm{P}$ (i.e., they will not be talking past each other via $\mathrm{P}$ ) if and only if each adopts throughout their discussion a willingness to suppose that the conception she has of $\mathrm{P}$ (which she in fact takes to be correct), if she has one at all, is not correct, and that some other unique conception (perhaps that of the other interlocutor, perhaps a third conception had by neither) is correct (Goodman 2007: 322).}

It seems easy to find a counterexample for this explication. Goodman's explication obviously implies

$\exists x(x$ is an interlocutor $\wedge x$ is not willing to suppose that his conception of $P$ is not correct.) $\rightarrow$ (The interlocutors are talking past one another via $P$.) 
Now, let us assume two dogmatic and stubborn interlocutors with the same conception of an $F$. They will quickly manage to agree, for example, about what the meaning of ' $F$ ' is. Moreover, they would clearly not talk past each other via ' $F$ ' either in their agreement. But in this example at least one interlocutor is not willing to suppose that his conception is not correct, thus the antecedent of the conditional above is satisfied, but there is nevertheless (intuitively) no talking past one another among the interlocutors via ' $F$ ', thus the consequent is not satisfied in the same example. But a conditional with a true antecedent and a false consequent is false, and since it is implied by Goodman's explication, the explication is false too.

I believe that the central confusion in Goodman's analysis is not to distinguish clearly enough between an explicit conception or theory that someone might endorse as a solution to an ontological or semantical problem, and the pre-theoretical, intuitive understanding that the interlocutors might have of this (or of the terms within which they are discussing it) and that ultimately guides, for example, their classification of actual and hypothetical cases, but also their interpretation of what is said in the discussion. The Standard View should be the view that two philosophers (may) talk past one another if they use in their discussion a term that they attach two different meanings to; but, of course, what is relevant here is not (necessarily) what they explicitly believe (after their reconstructive attempts) what the meaning is that they attached to a term, but what the meaning in fact is that they have attached to a term.

Consider the following example: I might believe falsely that 'bachelor' in my idiolect does and always did refer to men (regardless, amongst everything else, of their marital status), you might falsely believe that 'bachelor' does and always did refer in your idiolect to unmarried people (regardless, amongst everything else of their gender), but provided we mean the same with 'bachelor' in our shared language, it could very well be possible for us (for example through the method of cases, testing our intuitive responses to these) to arrive at the true belief that 'bachelor' does and always did refer in our shared language to unmarried men. That we in the end might manage to arrive at a satisfactory result is due to the fact that we had a common implicit understanding of 'bachelor' to begin with, despite our different explicit definitions of that term that we started from. The degree to which we will be dogmatic about our initial (false) beliefs, in the light of what we both recognize as good evidence for the falsity of our beliefs, will certainly negatively influence the progress we can make in our inquiry, but it is not a communication failure. It is a failure of rationality of the discussing parties. The explicit beliefs about implicit meaning are, for the question of whether discussing parties happen to talk past one another, largely irrelevant, which is also the reason for Jeffrey Goodman's curious observation that philosophers might be talking past one another even if they are aware that they have different explicit reconstructions of, for example, the meaning of a predicate term, while the meaning of that term is the topic of discussion. The problematic sort of cases of talking past one another that Goodman wants to cover, namely those that constitute communication failures, do, of course, not occur with both parties in the discussion being aware that they in fact use a term with two distinct meanings. You cannot talk past one another and know it. 
Because Goodman concentrates on the explicit beliefs we have about the meanings of our terms, he misses this. He also rejects the Standard View too quickly because of this confusion. Just as we can arrive at a coherent reconstruction of the meaning of 'bachelor' in our idiolect, if there is a common idiolect with respect to that term, we, however, will not make progress in this project if there is no such shared meaning. Our willingness to suppose (be it on one side or both) that our respective conception is wrong will be of absolutely no help here. In this case we will, just as Greta and Hannah in Goodman's example above, exchange our cases and purported counterexamples without coming to terms over how to classify them correctly. The Standard View correctly implies that we will be talking past one another then. Talking past one another (in any sense) is not a problem of dogmatism, but a problem of shared meaning (or, rather, the lack of it). If ontological disputes turn out to be merely verbal with the disagreeing parties just talking past one another, then this is not due to certain character deficits that all these ontologists happen to share (like being inexplicably stubborn and unwilling to admit mistakes).

\section{Explicating the standard view}

According to the Standard View, a verbal dispute is grounded in meaning. A common proposal that attempts to capture this idea is the following (see (Chalmers 2011: 519) for a reconstruction):

The Standard View. A dispute over a sentence $S$ is verbal iff $S$ expresses distinct propositions $p$ and $q$ for the two parties, so that one party asserts $p$ and the other denies $q$, and the parties agree on the truth of $p$ and $\neg q$.

But this is problematic for two reasons. The first reason is that not all verbal disputes are about an isolated sentence, such that one party in the dispute utters that sentence and the other utters its negation. Typically, philosophical disputes are more complex than that.

The second, more important reason is that the propositions that sentences express is not (just) a matter of the speakers' beliefs. Here are two examples, one from a paper by Brendan Balcerak Jackson, the other an adaptation from an example by Alan Sidelle that illustrate the point:

The first concerns the expression 'billion'. In American English this term unambiguously denotes the number $10^{9}$. Native speakers of German sometimes assume that 'billion' is the English translation of the nearly homophonous German term 'Billion', as do speakers of Spanish concerning their term 'billòn' and speakers of Italian concerning their term 'bilione'. But this is a mistake; the latter terms all denote the larger number $10^{12}$. Imagine, then, the following exchange between native American Englishspeaker Fozzy and bilingual native German-speaker Guido:

Fozzy: There are currently more than seven billion people living on earth. 
Guido: No way! There are far fewer than seven billion people living on earth right now.

Arguably, this dispute fails to meet the conditions for being narrowly verbal. Both Fozzy and Guido are speaking ordinary American English, and both intend to use 'billion' with the meaning that it has in the wider English-speaking community. Thus Fozzy asserts the proposition that there are more than $7 \times 10^{9}$ people living on earth, while Guido asserts the genuinely contradictory proposition that there are fewer than $7 \times 10^{9}$. Nonetheless, their dispute is intuitively merely verbal. They do not really disagree about the non-linguistic facts concerning the world population, and their dispute merely arises because of Guido's confusion about the word 'billion' (Balcerak Jackson 2014: 34-35).

Here is the second case:

Suppose that Rolf and Scooter have just watched a movie starring Burt Lancaster and Kirk Douglas. Rolf is not very familiar with the old Hollywood stars, and he has the image of Burt Lancaster in his mind, and is thinking of Lancaster's behavior in the film, when he utters the following:

Rolf : Kirk Douglas was really menacing, wasn't he?

Scooter, a fan of old movies who knows all the stars, responds:

Scooter: No, Douglas wasn't menacing. Burt Lancaster was the really menacing one.

Familiar considerations from the theory of reference lead to the conclusion that 'Kirk Douglas' in Rolf's mouth refers to Kirk Douglas, just as it does in Scooter's mouth and the mouths of other ordinary English speakers. So even though Rolf intends to refer to Burt Lancaster when he utters 'Kirk Douglas is menacing', what he actually asserts is that Kirk Douglas is menacing. And of course it is this proposition that Scooter contradicts with his assertion. Here, too, the conditions of the simple account are not met; but here, too, the dispute is intuitively merely verbal. (Balcerak Jackson 2014: 35)

Thus, in order to arrive at a satisfactory account of merely verbal disputes, we need to get around the problems posed by meaning externalism. David Chalmers (2011: 522) suggests the following gloss:

David Chalmers' account of Broadly Verbal Disputes. A dispute over $S$ is (broadly) verbal when for some expression $T$ in $S$, the parties disagree about the meaning of $T$, and the dispute over $S$ arises wholly in virtue of this disagreement regarding $T$.

Chalmers explains the gloss as follows: 
This gloss on a broadly verbal dispute works best if we assume a version of the common view that whenever speakers use an expression, they do so with beliefs about the expression's meaning, where these beliefs may be tacit beliefs rather than explicit beliefs. In cases of full competence, it is arguable that speakers use expressions with tacit knowledge of an expression's meaning. Then any case along the lines above ... will plausibly involve a disagreement about meaning, in that it will involve differing beliefs (perhaps tacit beliefs) about the meaning of a key term ... (Chalmers 2011: 522).

But note that there are at least two problems with this view. The first problem is that it requires at least tacit metalinguistic belief for any use of an expression. Now, even for tacit belief, concepts are required, namely those concepts that feature in the metalinguistic belief. Empirical evidence on the acquisition of linguistic competence on the one hand and the ability to make metalinguistic judgments on the other, suggests that the latter is acquired later (e.g. Doherty \& Perner 1998). Thus, it is simply not plausible to assume that whenever speakers use an expression, they do so with beliefs about the expression's meaning. Young children use expressions, often quite successfully and arguably fully competent even though they might not have the concepts acquired yet to even have tacit metalinguistic beliefs.

The second problem seems to be that externalism about meaning just extends (at least on many views) to externalism about mental content. Hence, Guido plausibly believes that 'There are currently more than seven billion people living on earth' means that there are currently more than seven billion people living on earth, and Rolf believes that 'Kirk Douglas' refers to Kirk Douglas. In other words, for the proposal to work we need to have a notion of narrow mental content in order to explain in which ways the interlocutors can disagree in their metalinguistic beliefs.

These two problems seem to suggest that we can do better by simply locating the disagreement in narrow meaning of the expressions themselves rather than in broad beliefs about them. Before we leave Chalmers, we should look at an alternative gloss that he considers in a footnote (and which, I believe, is closer to the truth) (Chalmers 2011: 524, footnote 6):

\section{David Chalmers' counterfactual account of Merely Verbal Disputes.} A dispute over $S$ is broadly verbal when for some term $T$ in $S$, if the parties were to agree over the meaning of $T$, then they would (if reasonable) agree over the truth of $S$.

As Chalmers explains, this definition actually suggests a heuristics for detecting and resolving verbal disputes by - what Chalmers calls - The Method of Elimination:

To apply [the method of elimination] to a dispute over a sentence $S$ that is potentially verbal with respect to term $T$, one proceeds as follows. First: one bars the use of term $T$. Second: one tries to find a sentence $S^{\prime}$ in the newly restricted vocabulary such that the parties disagree nonverbally over $S^{\prime}$, and such that the disagreement over $S^{\prime}$ is part of the dispute over $S$. 
Third: if there is such an $S^{\prime}$, the dispute over $S$ is not wholly verbal, or at least there is a substantive dispute in the vicinity. If there is no such $S^{\prime}$, then the dispute over $S$ is wholly verbal (except in the special case of vocabulary exhaustion...) (Chalmers 2011: 526-527).

There is a lot to like in Chalmers' analysis, and I have only two modifications to suggest. One concerns the identification of disputes. I agree with Carrie Jenkins that disputes should be characterized in behavioristic terms. However, if we take that position, then Chalmers' definition allows that two parties display dispute-behavior, without being seriously engaged in a dispute. As Carrie Jenkins argues, a case in which I am only apparently disputing with you over the truth of some sentence $S$, because, say, I'm playing the devil's advocate, or perhaps because we are both actors in a theater play, is not a verbal dispute in the sense intended. However, Chalmers' definition seems to count it as a verbal dispute, because if reasonable we would agree over the truth of $\mathrm{S}$, and in fact we do for any term $T$ in $S$.

Carrie Jenkins suggests a characterization of a 'merely verbal dispute' that tries to capture this idea in requiring that the parties of the prima facie dispute must be sincerely engaged in it:

Carrie Jenkins' account of Merely Verbal Disputes. Parties $A$ and $B$ are having a merely verbal dispute iff they are engaged in a sincere prima facie dispute $D$, but do not disagree over the subject matter(s) of $D$, and merely present the appearance of doing so owing to their divergent uses of some relevant portion of language (Jenkins 2014: 12).

However, this definition invites another reply. There still might be disputes that just appear to be disputes, but really are not, even if we require that the parties in the disputes are seriously engaged in it. Take the Quine-Carnap dispute about whether or not ontology is a feasible enterprise. According to some authors (as for example (Price 2009)), Quine and Carnap both agreed that the only way to answer questions about what there is, is to see what our best scientific theory is quantifying over. Carnap thought that it would be a bad idea to call that enterprise 'ontology', while Quine thought it wouldn't harm. The different choice of terminology led many philosophers of the last and this century to the false belief that Quine showed in "On What There Is" that - despite Carnap's criticism - ontology, in the sense in which Carnap wanted to deflate it, is possible after all, and that there is a Carnap-Quine controversy about the status of ontology in this sense.

Let us assume that this historical account is correct and exhaustive, and that Carnap and Quine were both aware of the fact that they were in agreement about how to answer meaningful questions about what there is. Then this would be an instance of a merely apparent dispute: it only appears that Carnap and Quine had a dispute about ontology, when in fact they were both in total agreement. That this appears to be a dispute is true only from a third-person perspective - according to the story, the proponents involved did not themselves believe that they were disagreeing. Thus, this notion of an 'apparent' dispute can and should presumably be characterized in 
behavioristic terms. There would be some justification to call this particular merely apparent dispute 'merely verbal', since the appearance of a dispute is caused by the fact that the proponents in the dispute use the central terminology (in particular the word 'ontology') with different meanings. However, I do not think that we should consider it a verbal dispute. As we said in the beginning, we have the intuition that the appearances must be misleading for at least the participating parties, not only for third parties.

Thus, although I believe that Jenkins is right in requiring that a dispute should be analyzed in behavioristic terms, it cannot be wholly characterized without recourse to the beliefs of the participating parties. In particular, I think it cannot be analyzed without requiring that the dispute is grounded in some sort of subjectively felt disagreement from the perspectives of the disputants.

This leads me to a second point in which I do not agree with Chalmers and Jenkins. While Chalmers requires resolvability of verbal disputes, Jenkins does not want to require resolvability for merely verbal disputes. I believe that Chalmers is right to require resolvability, but I am not sure about his qualification to the vocabulary. Perhaps Chalmers is right that it might happen that we cannot find a sentence $S^{\prime}$ in different vocabulary to express our disagreement, because we exhausted the terminology of our language. Perhaps there are cases, where it is then not possible to introduce just new, refined terminology. In these cases there is a danger of declaring something to be a verbal dispute, when in fact the disagreement is real.

However, I think that there is a complementary worry that Chalmers does not seem to address, namely that there is a mismatch of fundamental concepts such that we do mean different things with certain fundamental terms, but cannot introduce the relevant terminological distinction to see this, because we lack the possibility to acquire the relevant concepts. Let us look at an example that Chalmers is using in a different paper (Chalmers 2009).

Let us suppose that for Martians, but not humans, common sense ontology includes arbitrary mereological sums. Faced with two apples on a bare table and asked, 'How many objects are on the table', humans and Martians will usually make the following ordinary assertions...:

Humans: There are exactly two objects on the table.

Martians: There are exactly three objects on the table (Chalmers 2009: 86).

Now, given that Martians and humans are disagreeing because they are using two different commonsense ontologies, it might seem that this disagreement could be resolved by Chalmers' suggestion to rephrase the issue in other terms, banning certain vocabulary. So, Martians and humans might resolve the matter by saying something like:

It depends on how you count objects. The way you count objects, you're right; the way I count objects, I'm right. We could put things neutrally by saying that there are two h-objects and three m-objects (Chalmers 2009: 87). 
Although that might be a way for them to resolve the issue, it might just as well be that even after this terminological distinction is in place, the disagreement persists at an ontological level. And the reason for that persistence might be that Martians and humans have in their respective conceptual frameworks two different primitive concepts of existence. On the basis of their concept, the human will insist that really there are no m-objects, while the Martian will insist that although there are two h-objects on the table, these do not exhaust all the objects that really are on that table. According to that story, the respective existence concepts are primitive, and hence not further analyzable by the disagreeing parties. In other words: they will not find a way to resolve that dispute by moving to another vocabulary.

In this case, Chalmers' definition considers the case a substantial dispute, but it seems to me that it is not. The fact that the disagreement is at a level of fundamental concepts rather than at a level of less-fundamental concepts does not all of the sudden introduce any external substance into the dispute. The Martian and the human still are not really disagreeing, just talking past one another, although they are not any more in a position to resolve this problem terminologically.

However, I agree that this is not a 'merely verbal dispute' then either, because a 'merely verbal dispute', perhaps in contrast to a 'merely conceptual dispute' or 'merely conceptual disagreement' should require easy resolvability. I suggest that we need more than just a distinction between verbal and substantial disputes. I will try to provide definitions that can capture these ideas.

\section{Verbal disputes and conceptual disagreements}

I will suggest to defined three cognate notions. The notion of 'talking past one another' that I consider the broadest of these notions, the notion of a 'conceptual disagreement' or 'conceptual dispute', and the notion of a 'merely verbal dispute'. The notion of 'talking past one another' that I wish to explicate is more limited than the notion as it is used in ordinary language. I try to capture a meaning of 'talking past one another' that denotes a communication failure of a specific sort. Ordinary language also uses 'talking past one another' (at least) also (a) in order to refer to something that doesn't constitute a proper communication failure, as well as (b) in order to refer to communication failures of a different specific kind that we do not have in mind when we want to say of philosophers that they are talking past one another.

(a) According to ordinary usage, it seems coherent to say that two interlocutors are 'talking past one another' intentionally. Since in these cases there are no communication-intentions with respect to the subject matter that the interlocutors are 'talking past one another' about, there also is no communication failure in the sense that we try to explicate here. Hence our explication will not recognize such cases as cases of talking past.

(b) According to ordinary usage, interlocutors are talking past one another when they are pursuing different communication aims (and are unaware of it). For 
an example, let us assume that $A$ and $B$ have a small fight that started from the question whether they should go to a football match or a theater performance on next Saturday afternoon. While $A$ might believe that they are arguing continuously about the initial conflict of interests (such that this conflict could be resolved for example by $A$ agreeing to $B$ 's interests to go to the theater), $B$ might in fact be continuing the discussion with a different aim, such that this conflict could not be resolved for example by $A$ merely agreeing to $B$ 's interests to go to the theater, but rather by $A$ 's 'insight' that they should have considered $B$ 's interest in the first place. In this case $A$ and $B$ are in some sense 'talking past one another', but not because they would be using terms with different meaning, but rather because they do not agree about what the topic of their conversation is. $A$ believes that this is about what to do on Saturday afternoon, while $B$ takes the argument to be about how $A$ should be making their plans generally. This is certainly a communication failure, but not the communication failure that we typically want to refer to when we say about philosophers that they are talking past one another (as in the cases of ontological or logical pluralism). Again, our explication here will not include such cases of 'talking past'.

Let us first distinguish merely terminological from conceptual disputes. In order to do this, we need to introduce a notion of agreement and disagreement that make it possible to speak of agreement and disagreement between interlocutors regardless of whether the interlocutors are actually talking past one another. In order to do justice to the intuition that interlocutors might perhaps subjectively believe that they disagree when they are in fact talking past one another, but do not then objectively disagree, I will indicate the subjective character of this sort of disagreement with a subscript ' $\mathrm{s}$ '.

Agreement. There is agreement $_{\mathrm{s}}$ between two or more interlocutors about some subject matter $P$ iff all of the interlocutors believe that they can assent to the claims made about $P$ by all other interlocutors, given their interpretation of these claims.

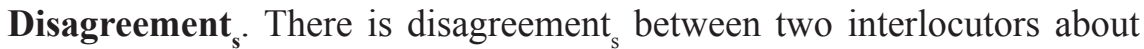
some subject matter $P$ iff at least one of the interlocutors believes that he can't assent to the claims made about $P$ by the other interlocutor, given his interpretation of these claims.

Given these notions, interlocutors might agree or disagree, although they in fact talk past one another, if their agreement (or disagreement) is based on a misinterpretation of the claims made by the other interlocutors.

On the basis of the notions of agreement and disagreement, we can now define a shallow conceptual disagreement:

Shallow conceptual disagreement. There is a shallow conceptual disagreement between some interlocutors regarding subject matter $P$, if

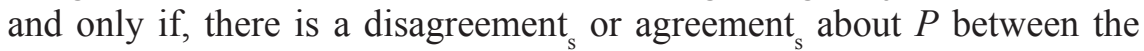
interlocutors such that some of the crucial terms, $T_{j}, \ldots, T_{m}$, in their discussion of $P$ are such that were different primary intensions of $T_{j}, \ldots, T_{m}$, which 
are conceptually available to all interlocutors, explicitly distinguished, the disagreement $_{\mathrm{s}}$ agreement $\mathrm{s}_{\mathrm{s}}$ would disappear, if the interlocutors were fully rational.

And also the notion of a merely verbal dispute:

Merely verbal dispute. Interlocutors are having a merely verbal dispute iff they are engaged in a sincere prima facie dispute $D$ which is due to a shallow conceptual disagreement between the interlocutors.

This gloss needs some explaining. First of all, we need a way to pick out the subject matter of a dispute, such that we can say that the interlocutors have a disagreement regarding that subject matter. This is by no means trivial. I will follow Brendan Balcerak Jackson (2014) here and assume that we can always identify a question that both interlocutors are trying to answer. We will also need to clarify what it means that a term is 'crucial in a discussion'. I leave this unanalyzed for now, but it should be clear that it does not mean that the term is used by both speakers or even by any of the involved interlocutors.

Thirdly, the notion of primary intension needs qualification. I take the relevant primary intensions to be functions from epistemic scenarios to extensions. Speakers may have different dispositions to evaluate the extensions of sentences (and other expressions) at epistemic scenarios even after ideal reflection. In this case, we may say that the speakers associate different narrow meanings with those expressions. If a disagreement $t_{\mathrm{s}}$ was due to such a difference, can be resolved by pointing that out, and is the sole cause of a dispute, then that dispute is merely verbal.

Finally, the definition refers to 'sincere prima facie disputes'. This is supposed to refer to both parties engaging in what seems to be dispute behavior, while both are sincere. This is the notion that Jenkins also had in mind. In order to guarantee that these apparent disputes are real disputes, we add that this behavior is caused by a subjective disagreement. Thereby we avoid the problems of Chalmers' and of Jenkins' account.

As we already saw above, some disagreements might persist even after different primary intensions of the crucial terms are distinguished. This does not mean, however, that the source of the residual disagreement is not conceptual. In that case we will be faced with a deep conceptual disagreement:

Deep conceptual disagreement. There is a deep conceptual disagreement between interlocutors and some subject matter $P$, if and only if, there is disagreement $_{\mathrm{s}}$ or agreement $\mathrm{s}_{\mathrm{s}}$ about $P$ between the interlocutors such that none (and no set) of the crucial terms, $T_{j}, \ldots, T_{m}$, in their discussion of $P$ is such that were different primary intensions of $T_{j}, \ldots, T_{m}$, which are conceptually available to all interlocutors, explicitly distinguished, the disagreement/agreement ${ }_{\mathrm{s}}$ would disappear, but at least one of the $T_{j}, \ldots$, $T_{m}$ is used by the interlocutors with a different primary intension, and the disagreement/agreement ${ }_{s}$ would not have occurred if that would not have been the case. 
The standard notion of talking past one another covers such deep conceptual disagreements as well as the shallow ones:

Talking past one another. Interlocutors are talking past one another about some subject matter $P$, if and only if, there is a shallow or deep conceptual disagreement between the interlocutors with respect to the subject matter $P$.

I think that by distinguishing these different notions we can accommodate all the intuitions we initially listed for merely verbal disputes, and have room for disagreements that are due to merely conceptual matters, but that are not merely verbal, in the sense that they could be resolved easily by the introduction of terminological distinctions.

Let us see how our definitions can deal with our examples. Greta and Hanna who could not agree about whether a kleptomaniac is acting freely have different dispositions to apply a term of their dispute to a hypothetical situation. In order to make progress they should distinguish different senses of acting freely and see whether the dispute goes away.

The dispute between Fozzy and Guido was due to Guido using 'billion' in a deviant way. Since the actual primary intension of the term is available to Guido, the dispute could easily be resolved. Likewise for the dispute between Rolf and Scooter. Note that in the latter case we do not need to assume that names have senses. It is sufficient to assume that names are associated with primary intensions that are completely anchored in the individual using the name.

\section{Deflating logic and ontology}

Now what about disputes about logic and ontology? On Chalmers' account, we can use the method of extinction in order to test whether a dispute is merely verbal. For a substantial dispute we will either find an alternative way of stating the disagreement, or we will reach bedrock. We will have reached bedrock, if the dispute is stated in so fundamental terms that we cannot find a more fundamental way of stating it, we simply ran out of vocabulary. It seems to me that on this account philosophical disputes get off the hook too easily. Since philosophical disputes are typically about fundamental questions, they also typically involve fundamental notions and fundamental terms. But then, disputes about logical constants, truth, and what exists should be almost automatically exempt from being potentially verbal. This does not seem right. I think the mistake is to be located in Chalmers' foundationalism about basic vocabulary. If we turn instead to primary intensions that an individual associates with an expression, we can make sense of differences in intensions, which seem to disappear on Chalmers' picture. Thus, disputes about logic and ontology are perhaps not merely verbal (which is good news for a logical pluralist), even though they can still be fully due to a conceptual disagreement (as opposed to a substantial disagreement) which, I take it, is good news for a logical or ontological anti-realist. 
However, whether these disputes are mere conceptual disagreements cannot be established on the basis of the heuristics discussed here - we only learned that they probably are not merely verbal but still could be merely conceptual. In other words, ontological and logical anti-realists will need independent evidence for their view. What evidence this could be we should leave for another paper.

Address:

Daniel Cohnitz

Department of Philosophy and Religious Studies

Utrecht University

Janskerkhof 13

3512 BL Utrecht

The Netherlands

E-mail: d.cohnitz@uu.nl

\section{References}

Balcerak Jackson, Brendan (2014) "Verbal disputes and substantiveness". Erkenntnis 79, 31-54.

Chalmers, David (2009) “Ontological anti-realism”. In D. J. Chalmers, D. Manley and R. Wassserman, eds. Metametaphysics: new essays on the foundations of ontology, 77-129. Oxford: Oxford University Press.

Chalmers, David (2011) "Verbal disputes". The Philosophical Review 120, 515-566.

Doherty, Martin J. and Josef Perner (1998) "Metalinguistic awareness and theory of mind: just two words for the same thing?". Cognitive Development 13, 279-305.

Goodman, Jeffrey (2007) "A critical discussion of talking past one another". Philosophy and Rhetoric $40,3,311-325$.

Jenkins, Carrie (2014) “Merely verbal disputes”. Erkenntnis 79, 11-30.

Price, Huw (2009) "Metaphysics after Carnap: the ghost who walks?” In D. J. Chalmers, D. Manley and R. Wassserman, eds. Metametaphysics: new essays on the foundations of ontology, 320-346, Oxford: Oxford University Press. 